\title{
Efficient approach for the chemoselective acetylation of alcohols catalyzed by a novel metal oxide nanocatalyst $\mathrm{CuO}-\mathrm{ZnO}$
}

\author{
Jalal Albadi a,*, Amir Alihosseinzadeh ${ }^{\mathrm{b}}$, Mehdi Mardani ${ }^{\mathrm{a}}$ \\ a Behbahan Khatam Alanbia University of Technology, Behbahan, Iran \\ b School of Chemical Engineering, University of Tehran, Tehran, Iran
}

\section{A R T I C L E I N F O}

Article history:

Received 19 October 2014

Accepted 10 December 2014

Published 20 March 2015

Keywords:

CuO-ZnO nanocatalyst

Alcohol

Chemoselective acetylation

Acetic anhydride

\begin{abstract}
A B S T R A C T
A new method has been developed for the chemoselective acetylation of alcohols with acetic anhydride in the presence of phenols using a novel, recyclable $\mathrm{CuO}-\mathrm{ZnO}$ nanocatalyst. The catalyst was synthesized using the co-precipitation method and characterized by $\mathrm{N}_{2}$ adsorption-desorption, $\mathrm{X}$-ray diffraction, scanning electron microscopy, transmission electron microscopy and energy dispersion scanning analyses. Furthermore, this catalyst could be recycled up to six times without significant loss in its activity.
\end{abstract}

(C) 2015, Dalian Institute of Chemical Physics, Chinese Academy of Sciences. Published by Elsevier B.V. All rights reserved.

\section{Introduction}

Methods for the protection of hydroxyl groups play a significant role in multistep organic syntheses because of the ease with which these transformations can be affected as well as the mild conditions required for the subsequent removal of the corresponding protecting groups [1]. The acetylation of hydroxyl groups is used in a variety of different applications, including organic synthesis and pharmaceutical chemistry, as well as numerous other industrial applications [2]. Although many useful procedures have been reported for the acetylation of hydroxyl groups [3-16], only a few procedures have been reported for the selective acetylation of alcohols in the presence of other functional groups such as phenols and amines. There is therefore still an urgent need for the development of new catalysts capable of affecting the chemoselective acetylation of hydroxyl groups in the presence of other reactive groups under mild conditions.
During the course of the last decade, nanocatalysts have emerged as a sustainable and competitive alternative to conventional catalysts. Nanoparticles possess a high surface-to-volume ratio, which enhances their activity and selectivity, while at the same time maintaining the intrinsic features of a heterogeneous catalyst [17]. In particular, the number of practical applications of nano metal oxides as catalysts in organic synthesis has increased considerably during the last 5 years because of the high catalytic activity resulting from their high surface area [18-20]. Nano metal oxides are effective alternatives to conventional solid heterogeneous catalysts, and can be readily synthesized from commercially available materials. Catalysts of this type have proven to be useful to chemists working in both academic and industrial research laboratories because they provide good activation of adsorbed compounds, enhanced reaction rates, high selectivity, facile work-up and good recyclability characteristics, as well as providing eco-friendly reaction

*Corresponding author. Tel/Fax:+98-671-2229969; E-mail: Chemalbadi@gmail.com 


$$
\mathrm{ROH} \underset{\mathrm{Ac}_{2} \mathrm{O}, \mathrm{CH}_{2} \mathrm{Cl}_{2} \text {, r.t. }}{\longrightarrow} \mathrm{ROAc}
$$

Scheme 1. Chemoselective acetylation of alcohols catalyzed by a $\mathrm{CuO}-\mathrm{ZnO}$ nanocatalyst.

conditions [21-23]. Because of their attractive properties, nano metal oxides have been used extensively as solid catalysts in a variety of organic reactions.

We previously reported the preparation of several nanocatalysts and an evaluation of their catalytic activity towards a wide variety of organic reactions [24-29]. In continuation of our research in this area, we herein wish to report the preparation of a $\mathrm{CuO}-\mathrm{ZnO}$ nanocatalyst, and its application for the chemoselective acetylation of alcohols with acetic anhydride at room temperature (Scheme 1).

\section{Experimental}

\subsection{Preparation of catalyst}

All of the chemicals used in this study were purchased from Merck (Germany). The catalyst was prepared using a co-precipitation method. Briefly, a $\mathrm{Na}_{2} \mathrm{CO}_{3} \cdot \mathrm{H}_{2} \mathrm{O}$ solution $(0.5$ $\mathrm{mol} / \mathrm{L})$ was added to a mixture of $0.03 \mathrm{~mol} / \mathrm{L} \mathrm{Cu}\left(\mathrm{NO}_{3}\right)_{2} \cdot 3 \mathrm{H}_{2} \mathrm{O}$ and $\mathrm{Zn}\left(\mathrm{NO}_{3}\right)_{3} \cdot 6 \mathrm{H}_{2} \mathrm{O}$ in water in a drop-wise manner with continuous stirring, and the resulting suspension was held at $\mathrm{pH}=8.5$ for $15 \mathrm{~min}$ at $65^{\circ} \mathrm{C}$. The mixture was then filtered and the filter-cake washed with warm deionized water. The precipitate was subsequently collected and dried at $100{ }^{\circ} \mathrm{C}$ for $12 \mathrm{~h}$ followed by calcination at $300{ }^{\circ} \mathrm{C}$ for $3 \mathrm{~h}$. A batch of the $\mathrm{ZnO}$ support was also prepared under these conditions for supplementary tests. The resulting catalyst was named $20 \mathrm{CuO} / \mathrm{ZnO}$, where the 20 refers to the weight percentage of $\mathrm{CuO}$ in the catalyst.

\subsection{Characterization}

Products were characterized by a comparison of their spectroscopic data (e.g., NMR and IR) and physical properties with those reported in the literature for the authentic compounds. The IR spectra were recorded on a PerkinElmer 781 spectrophotometer (USA). All of the NMR spectra were recorded on a Bruker Avance $400 \mathrm{MHz}$ NMR spectrometer (Germany). Yields refer to isolated pure products. X-ray diffraction (XRD) analyses were conducted on a Bruker AXS D8 advanced diffractometer to determine the structural properties of the catalyst. Samples for XRD analysis were scanned at $2 \theta$ values in the range of $10^{\circ}-80^{\circ}$ at a rate of $0.05^{\circ} / \mathrm{s}$ using $\mathrm{Cu} K_{\alpha}$ radiation $(\lambda=1.5406 \AA)$. The specific surface area of the samples was determined by $\mathrm{N}_{2}$ adsorption-desorption experiments using the BET method. BET tests were carried out using an automated gas adsorption analyzer (Tristar 3020, Micromeritics, USA). Prior to the tests, samples of the catalyst were degassed under vacuum at $150{ }^{\circ} \mathrm{C}$ for $2 \mathrm{~h}$. The morphological characteristics of the catalyst were investigated comprehensively by field emission scanning electron microscopy (SEM) and high-resolution transmission electron microscopy (HRTEM) techniques using a HITACHI S-4160 instrument (Japan) and a JEOL JEM-2100 (200 kV) microscope equipped with an energy dispersion scanning (EDS) analytical system (Japan). A GBC 906AA flame atomic absorption spectrophotometer (Australia) was used to determine the $\mathrm{Cu}$ contents of the catalysts.

\subsection{General procedure for the acetylation of alcohols}

A heterogenous mixture of alcohol (1 mmol), acetic anhydride $(1.2 \mathrm{mmol})$ and the $20 \mathrm{CuO}-\mathrm{ZnO}$ nanocatalyst $(0.05$ g) in $\mathrm{CH}_{2} \mathrm{Cl}_{2}(10 \mathrm{~mL})$ was stirred at room temperature. Upon completion of the reaction, as determined by TLC, the mixture was filtered to recover the catalyst. The catalyst was washed with $\mathrm{CH}_{2} \mathrm{Cl}_{2}(5 \mathrm{~mL})$ and then dried at $X{ }^{\circ} \mathrm{C}$ for $Y \mathrm{~h}$ before being used in consecutive runs. The combined organic layers were washed sequentially with $5 \%(w / v) \mathrm{NaHCO}_{3}$ solution and water and then dried over $\mathrm{MgSO}_{4}$. The solvent was then removed in vacuo to give the crude product as a residue, which was purified by column chromatography over silica gel to afford the pure desired products in high yield.

\section{Results and discussion}

The catalyst was characterized by XRD, $\mathrm{N}_{2}$ adsorptiondesorption, SEM, TEM, and EDS analyses.

Figure 1 shows the XRD patterns of the pure $\mathrm{ZnO}$ and 20CuO-ZnO samples. Several peaks in the XRD patterns were attributed to $\mathrm{ZnO}$ over a wide range of $2 \theta$ values, including those at $31.7^{\circ}, 34.3^{\circ}, 36.3^{\circ}, 47.3^{\circ}, 56.4^{\circ}, 62.8^{\circ}, 66.2^{\circ}, 67.8^{\circ}$, $69.0^{\circ}, 72.5^{\circ}$, and $76.9^{\circ}$, which were characteristics of the (100), (002), (101), (102), (110), (103), (200), (112), (201), (004), and (202) planes of ZnO (JCPDS 89-1397). 20CuO-ZnO catalyst revealed diffraction peaks at $2 \theta=35.5^{\circ}, 35.6^{\circ}, 38.7^{\circ}$, and $38.92^{\circ}$, which were attributed to the (002), (11i) , (111) and (200) planes of cubic CuO, respectively (JCPDS 05-0661).

The peaks intensities for the $\mathrm{ZnO}$ crystals in the $20 \mathrm{CuO}-\mathrm{ZnO}$ catalyst were lower and broader than those of the $\mathrm{ZnO}$ support. This result indicated that the $\mathrm{ZnO}$ crystals were less crystalline and smaller in size following the addition of $\mathrm{CuO}$, which could be attributed to the incorporation of $\mathrm{CuO}$ into the structure of

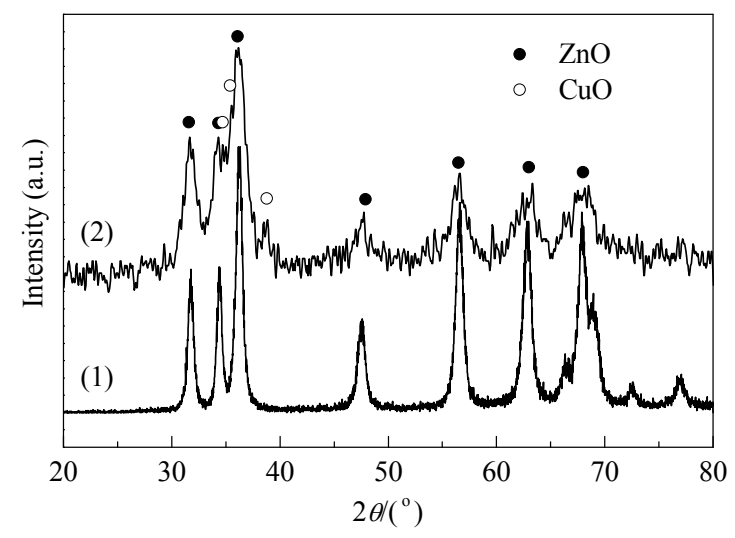

Fig. 1. XRD patterns of $\mathrm{ZnO}(1)$ and 20CuO-ZnO (2) nanocatalyst. 
Table 1

Structural properties of the $\mathrm{ZnO}$ and $20 \mathrm{CuO} / \mathrm{ZnO}$ samples prepared in the current study.

\begin{tabular}{|c|c|c|c|c|c|}
\hline \multirow{2}{*}{ Sample } & \multicolumn{2}{|c|}{ Crystal size* $(\mathrm{nm})$} & \multirow{2}{*}{$\begin{array}{c}S_{\mathrm{BET}} \\
\left(\mathrm{m}^{2} / \mathrm{g}\right)\end{array}$} & \multirow{2}{*}{$\begin{array}{l}\text { Pore volume } \\
\left(\mathrm{cm}^{3} / \mathrm{g}\right)\end{array}$} & \multirow{2}{*}{$\begin{array}{c}\text { Pore size } \\
(\mathrm{nm})\end{array}$} \\
\hline & $D_{\mathrm{CuO}}$ & $D_{\mathrm{ZnO}}$ & & & \\
\hline $\mathrm{ZnO}$ & - & 23 & 53 & 0.13 & 22.6 \\
\hline $20 \mathrm{CuO} / \mathrm{ZnO}$ & 8 & 12 & 89 & 0.32 & 17.9 \\
\hline
\end{tabular}

* Calculated by XRD.

ZnO. As shown in Table 1, the ZnO crystals were about 23 and $12 \mathrm{~nm}$ in size for the $\mathrm{ZnO}$ support and 20CuO-ZnO catalyst, respectively. Furthermore, the average size of the $\mathrm{CuO}$ crystals in the catalyst was calculated to be $8 \mathrm{~nm}$ using the Scherrer equation. The structural properties of the $\mathrm{ZnO}$ and $20 \mathrm{CuO} / \mathrm{ZnO}$ samples prepared in the current study are presented in Table 1.

The surface area of the $\mathrm{ZnO}$ support was determined to be $53 \mathrm{~m}^{2} / \mathrm{g}$, which increased to $89 \mathrm{~m}^{2} / \mathrm{g}$ following the loading of $20 \mathrm{wt} \% \mathrm{CuO}$ onto the support. As shown in Table 1, the pore volume of the 20CuO-ZnO catalyst increased compared with $\mathrm{ZnO}$ following the incorporation of $\mathrm{CuO}$, whereas its pore size decreased. The $\mathrm{N}_{2}$ adsorption-desorption isomers for the $\mathrm{ZnO}$ support and 20CuO-ZnO catalyst are shown in Fig. 2(a). Based on the IUPAC classification, the isotherms for these materials can be categorized as type IV with borderline type II characteristics and a type H3 hysteresis loop, indicating the presence of mesopores with a pore size distribution continuing into the macropore domain (Fig. 2(b)) [30]. Furthermore, type H3 hysteresis are usually only observed on solids containing aggregates or agglomerates of particles, which can lead to slit-shaped pores that are non-uniform in size and shape.

Figure 3 shows the SEM images of the $\mathrm{ZnO}$ support and 20CuO-ZnO catalyst. The $\mathrm{ZnO}$ micrograph showed that slit-like nanoparticles were aggregating on the surface of the $\mathrm{ZnO}$ support. Notably, SEM analysis of the 20CuO-ZnO material revealed that the incorporation of $\mathrm{CuO}$ into the $\mathrm{ZnO}$ support had a significant effect on the morphology of the catalyst, and the micrograph of the 20CuO-ZnO sample revealed the presence of nanoparticles agglomerates on the surface of the material with an average diameter of about $38 \mathrm{~nm}$.

Figure 4(a) shows a TEM image and the $\mathrm{CuO}$ particle size distribution of the 20CuO-ZnO nanocatalyst. More than 200 particles were measured to obtain an accurate particle size
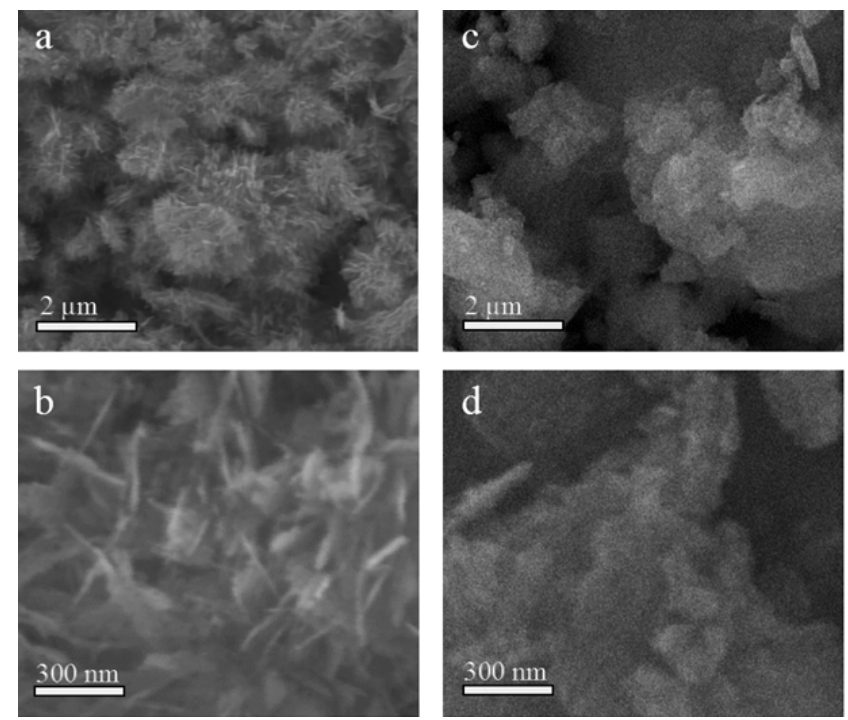

Fig. 3. SEM micrographs of the $\mathrm{ZnO}(\mathrm{a}, \mathrm{b})$ and 20CuO-ZnO (c,d) samples.

distribution. The CuO nanoparticles were found to be highly dispersed on the catalyst surface. The inset in Fig. 4(a) shows the particle size distribution of the $\mathrm{CuO}$ nanoparticles, where the average $\mathrm{CuO}$ particle size was determined to be about 4.4 $\mathrm{nm}$. HRTEM image of the 20CuO-ZnO catalyst is shown in Fig. 4(b). The reflections with $d$-spacing values of 0.282 and 0.252 $\mathrm{nm}$ correspond to the $\mathrm{ZnO}(100)$ and $\mathrm{CuO}$ (11i) lattice planes, respectively. The EDS results were found to be in good agreement with the nominal $\mathrm{Cu}$ loadings from the preparation process.

The reaction of benzyl alcohol with acetic anhydride was selected as a model reaction and conducted under a variety of different conditions in the presence of the $20 \mathrm{CuO}-\mathrm{ZnO}$ nanocatalyst to determine the optimal conditions for this transformation. The performances of various $\mathrm{CuO}-\mathrm{ZnO}$ nanocatalysts containing different amounts of $\mathrm{CuO}$ (i.e., 5, 10, and $20 \mathrm{wt} \%$ ) were evaluated for the acetylation of alcohols. The results revealed that the activity of the catalyst increased as the $\mathrm{CuO}$ content increased, and that the $20 \mathrm{Cu}-\mathrm{ZnO}$ catalyst gave the highest yield of $92 \%$ over the shortest reaction time (15 min). Optimization experiments revealed that the best results were obtained in the presence of $0.05 \mathrm{~g}$ of the $20 \mathrm{CuO}-\mathrm{ZnO}$ nanocata-
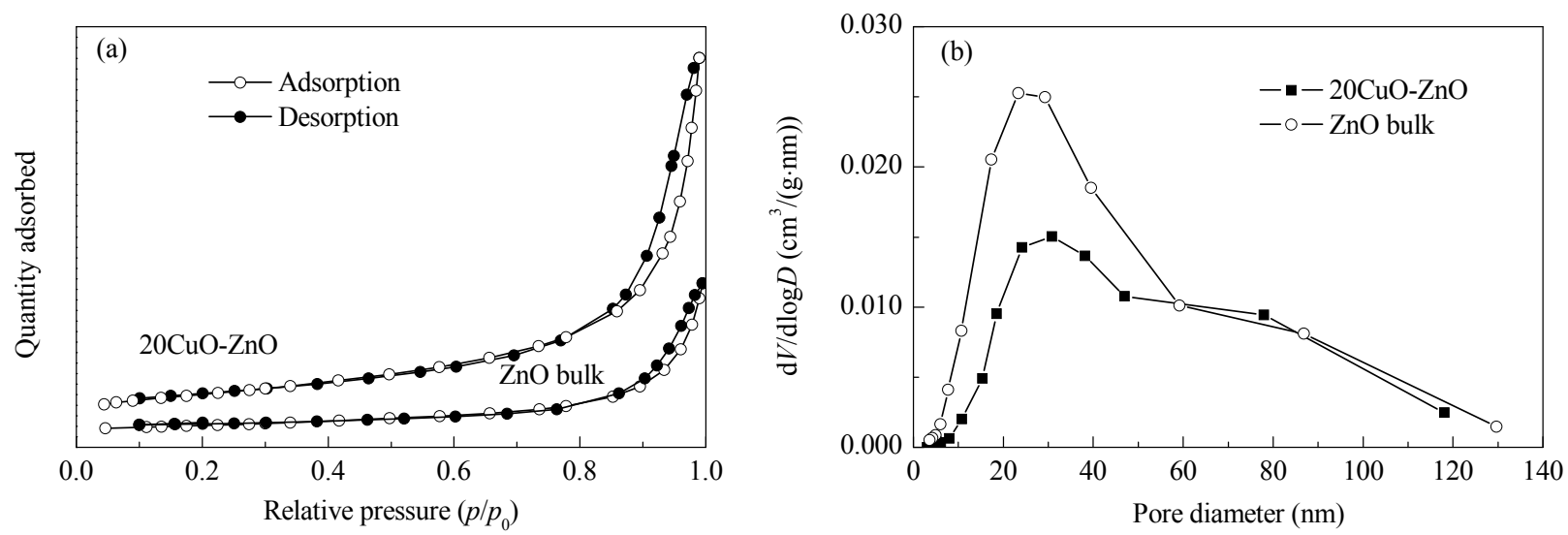

Fig. 2. $\mathrm{N}_{2}$ adsorption-desorption isotherms (a) and pore size distributions (b) of the $\mathrm{ZnO}$ and 20CuO-ZnO samples. 

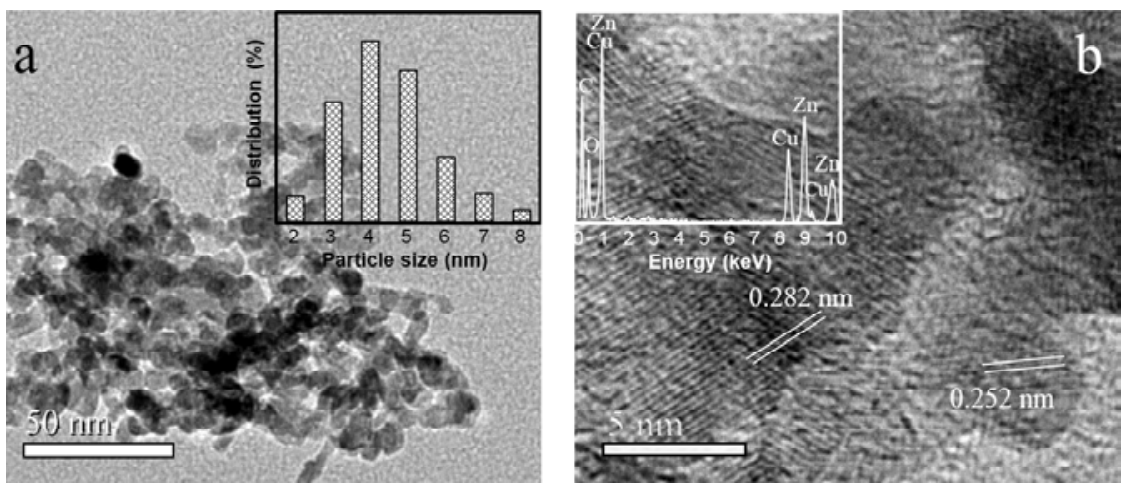

Fig. 4. TEM (a) and HRTEM (b) images of the 20CuO-ZnO nanocatalyst.

lyst at room temperature, when the relative molar ratio of the substrate to acetic anhydride was 1:1.2. With the optimized conditions in hand for the acetylation of alcohols, we proceeded to screen a wide range of different alcohols, including benzylic, primary, secondary, and tertiary alcohols. The results of these reactions revealed that all of the alcohols tested were converted to the corresponding acetates in excellent yields under the optimized conditions (Table 2). Benzylic alcohols bearing electron-donating groups were found to be the most reactive of all of the substrates tested and were converted to the corresponding acetates in the shortest reaction times. Furthermore, the reaction proceeded at a slower rate for aromatic substrates bearing an electron-withdrawing group (Table 2, entries 2-7).

The results of these experiments revealed that cyclic and linear alcohols were converted to the corresponding products in suitably high yields (Table 2, entries 14-25). Notably, the tertiary alcohol 1-adamantanol was also successfully acetylated in high yield to give the corresponding acetylated material (Table 2, entry 24). The acetylation of phenols with acetic anhydride was also investigated using the $20 \mathrm{CuO}-\mathrm{ZnO}$ catalyst. The results revealed that phenols did not react under the optimized reaction conditions (Table 1, entries 26-28). The selectivity of the catalytic system was evaluated using a mixture of alcohols and phenols. For this purpose, an equimolar mixture of benzyl alcohol and phenol was reacted with acetic anhydride in the presence of the 20CuO-ZnO catalyst. The results of this reaction revealed that it proceeded with absolute chemoselectivity towards the benzyl alcohol (Table 1, entry 29). This method could therefore be useful for the chemoselective acetylation of alcohols in the presence of phenols. A plausible mechanism of the reaction is shown in Scheme 2 .

The recyclability of a true heterogeneous catalyst is an important performance characteristic. The reaction of benzyl alcohol with acetic anhydride was selected as a model to investigate the recyclability of the $20 \mathrm{CuO}-\mathrm{ZnO}$ catalyst (Table 3 ). The results revealed that the catalyst could be reused up to six times without significant loss in its activity.

To highlight the efficiency of this new method, we compared the results obtained with our new 20CuO-ZnO nanocatalyst for the chemoselective acetylation of benzyl alcohol with the results reported for the same reaction using a wide range of different catalysts (Table 4).

Compared with several other catalysts reported for this
Table 2

Chemoselective acetylation of alcohols in the presence of the 20CuO-ZnO nanocatalyst.

\begin{tabular}{|c|c|c|c|c|}
\hline Entry & Substrate & Product & $\begin{array}{l}\text { Time } \\
\text { (min) }\end{array}$ & $\begin{array}{c}\text { Isolated } \\
\text { yield (\%) }\end{array}$ \\
\hline 1 & $\mathrm{C}_{6} \mathrm{H}_{5} \mathrm{CH}_{2} \mathrm{OH}$ & $\mathrm{C}_{6} \mathrm{H}_{5} \mathrm{CH}_{2} \mathrm{OAc}$ & 15 & 92 \\
\hline 2 & $3-\mathrm{NO}_{2} \mathrm{C}_{6} \mathrm{H}_{4} \mathrm{CH}_{2} \mathrm{OH}$ & $3-\mathrm{NO}_{2} \mathrm{C}_{6} \mathrm{H}_{4} \mathrm{CH}_{2} \mathrm{OAc}$ & 45 & 89 \\
\hline 3 & $4-\mathrm{NO}_{2} \mathrm{C}_{6} \mathrm{H}_{4} \mathrm{CH}_{2} \mathrm{OH}$ & $4-\mathrm{NO}_{2} \mathrm{C}_{6} \mathrm{H}_{4} \mathrm{CH}_{2} \mathrm{OAc}$ & 60 & 88 \\
\hline 4 & $2-\mathrm{ClC}_{6} \mathrm{H}_{4} \mathrm{CH}_{2} \mathrm{OH}$ & $2-\mathrm{ClC}_{6} \mathrm{H}_{4} \mathrm{CH}_{2} \mathrm{OAc}$ & 25 & 89 \\
\hline 5 & $4-\mathrm{ClC}_{6} \mathrm{H}_{4} \mathrm{CH}_{2} \mathrm{OH}$ & 4- $\mathrm{ClC}_{6} \mathrm{H}_{4} \mathrm{CH}_{2} \mathrm{OAc}$ & 20 & 92 \\
\hline 6 & $2,4-\mathrm{Cl}_{2} \mathrm{C}_{6} \mathrm{H}_{3} \mathrm{CH}_{2} \mathrm{OH}$ & $2,4-\mathrm{Cl}_{2} \mathrm{C}_{6} \mathrm{H}_{3} \mathrm{CH}_{2} \mathrm{OAc}$ & 20 & 92 \\
\hline 7 & $4-\mathrm{BrC}_{6} \mathrm{H}_{4} \mathrm{CH}_{2} \mathrm{OH}$ & 4- $\mathrm{BrC}_{6} \mathrm{H}_{4} \mathrm{CH}_{2} \mathrm{OAc}$ & 25 & 88 \\
\hline 8 & $2-\mathrm{MeOC}_{6} \mathrm{H}_{4} \mathrm{CH}_{2} \mathrm{OH}$ & $2-\mathrm{MeOC}_{6} \mathrm{H}_{4} \mathrm{CH}_{2} \mathrm{OAc}$ & 18 & 90 \\
\hline 9 & $3-\mathrm{MeOC}_{6} \mathrm{H}_{4} \mathrm{CH}_{2} \mathrm{OH}$ & 3- $\mathrm{MeOC}_{6} \mathrm{H}_{4} \mathrm{CH}_{2} \mathrm{OAc}$ & 15 & 92 \\
\hline 10 & $4-\mathrm{MeOC}_{6} \mathrm{H}_{4} \mathrm{CH}_{2} \mathrm{OH}$ & $4-\mathrm{MeOC}_{6} \mathrm{H}_{4} \mathrm{CH}_{2} \mathrm{OAc}$ & 12 & 93 \\
\hline 11 & $4-\mathrm{Me}_{3} \mathrm{C}_{6} \mathrm{H}_{4} \mathrm{CH}_{2} \mathrm{OH}$ & $4-\mathrm{Me}_{3} \mathrm{C}_{6} \mathrm{H}_{4} \mathrm{CH}_{2} \mathrm{OAc}$ & 15 & 90 \\
\hline 12 & $3-\mathrm{HOC}_{6} \mathrm{H}_{4} \mathrm{CH}_{2} \mathrm{OH}$ & $3-\mathrm{HOC}_{6} \mathrm{H}_{4} \mathrm{CH}_{2} \mathrm{OAc}$ & 15 & 93 \\
\hline 13 & $4-\mathrm{HOC}_{6} \mathrm{H}_{4} \mathrm{CH}_{2} \mathrm{OH}$ & 4- $\mathrm{HOC}_{6} \mathrm{H}_{4} \mathrm{CH}_{2} \mathrm{OAc}$ & 10 & 93 \\
\hline 14 & $\mathrm{C}_{6} \mathrm{H}_{5} \mathrm{CH}_{2} \mathrm{CH}_{2} \mathrm{OH}$ & $\mathrm{C}_{6} \mathrm{H}_{5} \mathrm{CH}_{2} \mathrm{CH}_{2} \mathrm{OAc}$ & 20 & 91 \\
\hline 15 & $\mathrm{C}_{6} \mathrm{H}_{5} \mathrm{CH}_{2} \mathrm{CH}_{2} \mathrm{CH}_{2} \mathrm{OH}$ & $\mathrm{C}_{6} \mathrm{H}_{5} \mathrm{CH}_{2} \mathrm{CH}_{2} \mathrm{CH}_{2} \mathrm{OAc}$ & 20 & 89 \\
\hline 16 & $\mathrm{C}_{6} \mathrm{H}_{5} \mathrm{CH}(\mathrm{OH}) \mathrm{CH}_{3}$ & $\mathrm{C}_{6} \mathrm{H}_{5} \mathrm{CH}(\mathrm{OAc}) \mathrm{CH}_{3}$ & 30 & 89 \\
\hline 17 & $\mathrm{CH}_{3} \mathrm{CH}(\mathrm{OH}) \mathrm{CH}_{3}$ & $\mathrm{CH}_{3} \mathrm{CH}(\mathrm{OAc}) \mathrm{CH}_{3}$ & 32 & 90 \\
\hline 18 & $\begin{array}{c}\mathrm{CH}_{3} \mathrm{CH}_{2} \mathrm{CH}_{2} \mathrm{CH}_{2} \mathrm{OH} \\
\mathrm{OH}\end{array}$ & $\underset{\mathrm{OAc}}{\mathrm{CH}_{3} \mathrm{CH}_{2} \mathrm{CH}_{2} \mathrm{CH}_{2} \mathrm{OAc}}$ & 30 & 89 \\
\hline 19 & & & 35 & 88 \\
\hline 20 & & & 30 & 87 \\
\hline 21 & & & 60 & 86 \\
\hline 22 & & & 25 & 90 \\
\hline 23 & & & 30 & 90 \\
\hline 24 & & & 70 & 88 \\
\hline 25 & & & 60 & 89 \\
\hline 26 & $\mathrm{C}_{6} \mathrm{H}_{5} \mathrm{OH}$ & $\mathrm{C}_{6} \mathrm{H}_{5} \mathrm{OAc}$ & 120 & 0 \\
\hline 27 & $4-\mathrm{BrC}_{6} \mathrm{H}_{4} \mathrm{OH}$ & $4-\mathrm{BrC}_{6} \mathrm{H}_{4} \mathrm{OAc}$ & 120 & 0 \\
\hline 28 & $4-\mathrm{MeOC}_{6} \mathrm{H}_{4} \mathrm{OH}$ & 4- $\mathrm{MeOC}_{6} \mathrm{H}_{4} \mathrm{OAc}$ & 120 & 0 \\
\hline 29 & $\mathrm{C}_{6} \mathrm{H}_{5} \mathrm{CH}_{2} \mathrm{OH}+\mathrm{C}_{6} \mathrm{H}_{5} \mathrm{OH}$ & $\mathrm{C}_{6} \mathrm{H}_{5} \mathrm{CH}_{2} \mathrm{OAc}$ & 15 & 91 \\
\hline
\end{tabular}

Reaction conditions: alcohol $1 \mathrm{mmol}$, acetic anhydride $1.2 \mathrm{mmol}$, catalyst $0.05 \mathrm{~g}$, room temperature, solvent $\mathrm{CH}_{2} \mathrm{Cl}_{2}$. 


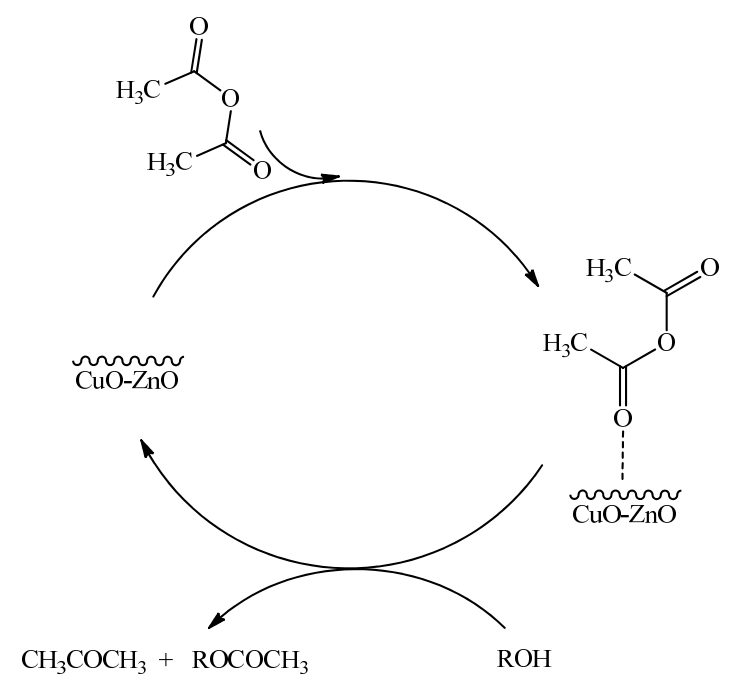

Scheme 2. Proposed mechanism for the acetylation of alcohols in the presence of a $\mathrm{CuO}-\mathrm{ZnO}$ nanocatalyst.

Table 3

Recyclability study for the 20CuO-ZnO nanocatalyst.

\begin{tabular}{lcccccc}
\hline Run & 1 & 2 & 3 & 4 & 5 & 6 \\
\hline Time (min) & 15 & 15 & 18 & 20 & 22 & 25 \\
Isolated yield (\%) & 92 & 90 & 90 & 89 & 88 & 87 \\
\hline
\end{tabular}

Reaction conditions: see Table 2.

transformation, the 20CuO-ZnO nanocatalyst promoted the reaction effectively to give the desired product in high yield over a short reaction time. This catalyst is inexpensive and easy to handle, and the acetylation of hydroxyl groups using this catalyst only required a low loading of the catalyst and a small excess of $\mathrm{Ac}_{2} \mathrm{O}$. Furthermore, the results of this study show that this catalyst could be used to achieve the chemoselective protection of alcohols in the presence of phenols. Notably, the catalyst could also be readily recovered by filtration and reused up to six times without any discernible decrease in the yield of the products.

\section{Conclusions}

We have developed a new, simple, and efficient procedure for the chemoselective acetylation of alcohols with $\mathrm{Ac}_{2} \mathrm{O}$ at room temperature using a novel recyclable $\mathrm{CuO}-\mathrm{ZnO}$ nanocatalyst. This newly developed catalyst could be recycled at least six times without any discernible loss in its activity. Furthermore, the ease of work-up and environmentally friendly nature of this procedure make it a useful and important addition to the currently available methods. Further work towards exploring the application of $\mathrm{CuO}-\mathrm{ZnO}$ nanocatalysts to other functional group transformations is currently underway in our laboratory.

\section{Acknowledgments}

We are thankful to the research council of Behbahan Khatam Alanbia University of Technology for supporting this work.

\section{References}

[1] Ghosh R, Maiti S, Chakraborty A. Tetrahedron Lett, 2005, 46: 147

[2] Humphrey J M, Chamberlin A R. Chem Rev, 1997, 97: 2243

[3] Shirini F, Zolfigol M A, Abedini M. Monatsh Chem, 2009, 140: 1495

[4] Leclercq L, Suisse I, Agbossou-Niedercorn F. Eur J Org Chem, 2010: 2696

[5] Singh S J, Kale S R, Gawande M B, Velhinho A, Jayaram R V. Catal Commun, 2014, 44: 24

[6] Tamaddon F, Amrollahi M A, Shrafat L. Tetrahedron Lett, 2005, 46: 7841

[7] Lopez I, Bravo J L, Caraballo M, Barneto J L, Silvero G. Tetrahedron Lett, 2011, 52: 3339

[8] Moghadam M, Tangestaninejad S, Mirkhani V, MohammadpoorBaltork I, Gharaati S. C R Chim, 2011, 14: 1080

[9] Osiglio L, Romanelli G, Blanco M.J Mol Catal A, 2010, 316: 52

[10] Khazaie A, Rostami A, Mantashlo F. Chin Chem Lett, 2010, 21: 1430

[11] Farhadi S, Panahandehjoo S. Appl Catal A, 2010, 382: 293

[12] Rajabi F, Luque R. Catal Commun, 2014, 45: 129

[13] Ghorbani-Choghamarani A, Pourbaharan N. Chin J Catal (催化学 报), 2012, 33: 1470

[14] Shirini F, Khaligh N G. Chin J Catal (催化学报), 2013, 34: 695

[15] Hajjami M, Ghorbani-Choghamarani A, Norouzi M. Chin J Catal (催 化学报), 2012, 33: 1661

[16] Javaherian M, Sabzi H E. Ind J Chem, 2014, 53B: 631

[17] Astruc D. Nanoparticles and Catalysis. Weinheim: Wiley-VCH, 2008

[18] Samantaray S, Pradhan D K, Hota G, Mishra B G. Chem Eng J, 2012, 193: 1

[19] Li S, Zhang W, So M H, Che H M, Wang C M, Chen R. J Mol Catal A, 2012, 359: 81

[20] Pinaka A, Vougioukalakis G C, Dimotikali D, Psyharis V, Papadopoulos K. Synthesis, 2012, 44: 1057

[21] Sarvari M H, Sharghi H.J Org Chem, 2004, 69: 6953

[22] Yin S F, Xu B Q, Wang S J, Ng C F, Au C T. Catal Lett, 2004, 96: 113

[23] Drexler M T, Amiridis M D. Catal Lett, 2002, 79: 175

[24] Albadi J, Razeghi A, Abbaszadeh H, Mansournezhad A.J Nanoparticles, 2013, 2013: 546194

[25] Albadi J, Mansournezhad A, Abbaszadeh H. J Chin Chem Soc, 2013, 60: 1193

[26] Albadi J, Mansournezhad A, Derakhshandeh Z. Chin Chem Lett, 2013, 24: 821

[27] Albadi J, Mansournezhad A, Azarian Z. Iran J Org Chem, 2013, 5:

Table 4

Comparison of the efficiency of the 20CuO-ZnO nanocatalyst with several other catalysts for the chemoselective acetylation of benzyl alcohol.

\begin{tabular}{|c|c|c|c|c|c|}
\hline Entry & Catalyst & Acylation agent & Time (min) & Isolated yield (\%) & Ref. \\
\hline 1 & $\mathrm{Cu}-\mathrm{BDC}$ & $\mathrm{Ac}_{2} \mathrm{O}(2 \mathrm{mmol})$ & 1440 & 87 & [5] \\
\hline 2 & $\mathrm{ZnAl}_{2} \mathrm{O}_{4}$ nanoparticles & $\mathrm{Ac}_{2} \mathrm{O}(10 \mathrm{mmol})$ & 18 & 90 & {$[11]$} \\
\hline 3 & ZnO & RCOCl (12 mmol) & 35 & 93 & [6] \\
\hline 4 & Nano ZnO & $\mathrm{CH}_{3} \mathrm{COOH}(5 \mathrm{ml})$ & 180 & 81 & [16] \\
\hline 5 & 20CuO-ZnO nanocatalyst & $\mathrm{Ac}_{2} \mathrm{O}(1.2 \mathrm{mmol})$ & 15 & 92 & this work \\
\hline
\end{tabular}




\section{Graphical Abstract}

Chin. J. Catal., 2015, 36: 308-313 doi: 10.1016/S1872-2067(14)60259-X

Efficient approach for the chemoselective acetylation of alcohols catalyzed by a novel metal oxide nanocatalyst CuO-ZnO

Jalal Albadi*, Amir Alihoseinzadeh, Mehdi Mardani

Behbahan Khatam Alanbia University of Technology, Iran; University of Tehran, Iran

$$
\mathrm{ROH} \underset{\mathrm{Ac}_{2} \mathrm{O}, \mathrm{CH}_{2} \mathrm{Cl}_{2} \text {, r.t. }}{\mathrm{CuO}-\mathrm{ZnO} \text { nanocatalyst }} \mathrm{ROAc}
$$

A new $\mathrm{CuO}-\mathrm{ZnO}$ nanocatalyst has been developed as an efficient recyclable catalyst for the chemoselective acetylation of alcohols.

693

[28] Albadi J, Razeghi A, Mansournezhad A, Azarian Z. J Nanostructure Chem, 2013, 3: 85
[29] Albadi J, Shiran J A, Mansournezhad A. JChem Sci, 2014, 126: 147

[30] Albadi J, Razeghi A, Alihoseinzadeh A. Catal Commun, 2014, 49: 1

[31] Sheldon R A. Catal Today, 1987, 1: 351 